\title{
Application of the mean individual biomass of ground beetles (Coleoptera: Carabidae) to assess the assemblage successions along areas of recent glacier retreats
}

\author{
Mauro GOBBI \\ Department of Invertebrate Zoology and Hydrobiology, MUSE - Museo delle Scienze, Corso del Lavoro e della Scienza, 3 , \\ I- 38123 Trento, Italy; e-mail: mauro.gobbi@muse.it
}

Key words. Coleoptera, Carabidae, primary succession, melting glaciers, body length, taxonomic distinctness, the Alps

\begin{abstract}
Glacial retreat creates new habitat which is colonized by plants and animals during the process of primary succession. Traditionally, invertebrate succession along the glacier forelands has been spatially and temporally described by the following predictors: species richness, diversity/similarity indices and species traits. In this paper another approach is used and applied to carabid beetle assemblages in two alpine glacier forelands. It utilizes mean individual biomass (MIB), which is considered by several authors to be a good indicator of habitat successional stages. MIB increased with time since deglaciation and this is related to species turnover along the glacier forelands. Specifically, MIB is able to separate early from late successional stages. The former are characterized by carabid assemblages with low MIB values and species typical of pioneer habitats, while the latter are characterized by carabid assemblages with high MIB values and species typical of stable and mature habitats. Therefore, MIB seems to be a sensitive indicator of carabid beetle successional stages also along the glacier forelands.
\end{abstract}

\section{INTRODUCTION}

Retreating glaciers are considered to be key indicators of global warming (Oerlemans, 2005). During their retreat they leave behind spatially ordered moraines on which primary stages of succession occur (Matthews, 1992). Succession is defined as a non-seasonal, directional, continuous and predictable process of colonization by populations of species in a given area (Begon et al., 1991). Succession is driven by species turnover in which species characteristic of early successional stage are replaced by those characteristic of mid to late successional stages (Schwerk et al., 2006). Glacier forelands are unique model systems for studying the action of climate change on soil communities (Bardgett et al., 2005). It is assumed that plots of different ages represent different stages in the development of the coenoses (Bardgett et al., 2005).

Research on invertebrates along the alpine glacier forelands has shown that the colonization and succession processes are deterministic and directional (Kaufmann, 2001; Hodkinson et al., 2004; Gobbi et al., 2006). As a consequence of their passive and active dispersal mechanisms and high reproductive rates, different taxa react in different ways to environmental changes triggered by the retreat of glaciers (Kaufmann, 2002; Brambilla \& Gobbi, 2014).

Thanks to their ability to respond to abiotic and biotic variation in their environments (Lövei \& Sunderland, 1996), carabid beetles (also called ground beetles; Coleoptera: Carabidae) are model organisms for investigating the patterns of colonization of glacier forelands (see: Gobbi et al., 2007; Bråten et al., 2012; Schlegel \& Riesen, 2012). In particular, Hodkinson \& Jackson (2005) highlighted the potential for using ground beetles to monitor environmental changes in montane ecosystems.
Several approaches are used to describe the successions in relation to time since deglaciation, the most common being diversity indices (e.g. Shannon's Index) (Kaufmann, 2001), species richness (Braten et al., 2012; Schlegel \& Riesen, 2012), functional traits (Gobbi et al., 2010) and occurrence probability (Brambilla \& Gobbi, 2014).

This paper uses a new approach, previously not applied in areas from which glaciers have retreated since the Little Ice Age $\left(16^{\text {th }}-19^{\text {th }}\right.$ century AD). The approach consists of describing carabid beetle succession along the glacier forelands in terms of the mean individual biomass (MIB) (Schwerk \& Szyszko, 2007a, after Szyszko, 1983) of carabid assemblages in areas differing in the time since deglaciation. MIB can be determined either by weighing live individuals or using a formula that describes the relationship between body length and live biomass of a carabid beetle (Szyszko, 1983). MIB is considered to be a simple yet suitable method for assessing the carabid fauna in a given habitat. This method can be used to indicate differences in the stage of succession between areas, and previous research carried out in different areas in Europe indicate that the MIB index can be used as a suitable measure for assessing the stage of succession of habitats (Szyszko et al., 1996; Serrano \& Gallego, 2004; Schwerk et al., 2006; Càrdenas \& Hidalgo, 2007). If large species dominate habitats in an advanced stage of succession, MIB should increase with succession. MIB is already used in studies in forest and open (agroecosystem) habitats (e.g. Szyszko et al., 1996; Serrano \& Gallego, 2004; Schwerk et al., 2006) and in long-term habitat monitoring (Szyszko et al., 2000).

Specifically, this paper has a dual purpose to test whether: (a) MIB values of carabid assemblages, collected along the glacier forelands change in terms of the number of spe- 
cies and the taxonomic distinctness of each assemblage and (b) MIB values depend on spatial and temporal stages.

\section{MATERIAL AND METHODS}

\section{Study area and sampling protocol}

This study was carried out in the central-eastern Italian Alps, where carabid beetle assemblages in two neighboring glacier forelands (Forni glacier foreland $-46^{\circ} 25^{\prime} \mathrm{N}, 10^{\circ} 34^{\prime} \mathrm{E}$ and Cedec glacier $-46^{\circ} 27^{\prime} \mathrm{N}, 10^{\circ} 35^{\prime} \mathrm{E}$ ) were investigated. Detailed information on the types of vegetation growing in the bottom and on the sides of the Forni valley is reported in Gobbi et al. (2006) and for the Cedec valley in Gobbi et al. (2010). Carabid beetles were collected during 2004 and 2005 in the Forni glacier foreland (Gobbi et al., 2007) and in 2007 in the Cedec glacier foreland (Gobbi et al., 2010). Carabids were sampled using pitfall traps (108 in the Forni glacier foreland and 30 in the Cedec glacier foreland). Pitfall traps consisted of plastic cups ( $7 \mathrm{~cm}$ diameter) baited with a standard mixture of wine-vinegar and salt to preserve the catch. The traps were reset every 20 days during the snow-free period (July-September). The sampling sites were in the proglacial areas, from the glacier terminus to areas that were not covered by glaciers during the Holocene (Late Glacial substrata). The traps were located on terrain adjacent to the glacial front, on recent and stabilized moraines and on Late Glacial substrata. Each trap was located in a place of known substratum age (time since deglaciation). The time span ranged from sites deglaciated since one year, to areas not covered by glaciers in the Little Ice Age, and therefore more than 155 years old (Late Glacial substrata) For the analyses I defined the age of Late Glacial substrata as 10,000 years old, although the precise date is not available (the end of the Late Glacial Period was about 10,500 year ago) and log-transformed the data on time since deglaciation before carrying out the analyses.

\section{Data analyses}

The datasets for the two glacier forelands (see Gobbi et al., 2007,2010 ) were merged to obtain a single matrix in which the columns are the species sampled and the rows the traps. A total of 23 traps contained no specimens. Analyses were therefore carried out using data for the 115 traps that caught carabids; a total of 23 species and 910 individuals were caught by these traps (Supplementary file S1).

Mean individual biomass (MIB) was calculated by dividing the biomass of all the carabids sampled by the number of specimens caught in a trap. Biomass values (expressed in milligrams) were obtained using the regression equation, reported in Schwerk \& Szyszko (after Szyszko, 1983), which describes the relationship between body length of a carabid $(x)$ and its biomass $(y)$ :

$\ln y=-8.928+2.555 \times \ln x$

This regression equation defines the positive correlation $\left(\mathrm{R}^{2}=\right.$ 0.96) between body length and body mass (Szyszko, 1983). Body length was the distance from the margin of the labrum to the apex of the elytra, and was expressed as the average body length for each species. Carabid beetles were identified to species following Hůrka (1996), Pesarini \& Monzini (2010) and Pesarini \& Monzini (2011). Hancock \& Legg (2012) report that pitfall trap effectiveness and body mass could be strongly correlated and propose a statistical method to correct pitfall trap catches for this effect. However, as Schwerk \& Szyszko (2007a) did not suggest any prior correction before applying the MIB index I did not correct the index.

Taxonomic distinctness was calculated using the equations in Clarke \& Warwick (1998) including confidence intervals computed from 1000 random replicates taken from the pooled data set (all traps). Taxonomic distinctness is the average path length between any two randomly chosen individuals, assuming they are different species; it can be considered as a measure of pure taxonomic relatedness (Clarke \& Warwick, 1998). This index depends on the taxonomic information considered. The taxonomic matrix used for the calculation of taxonomic index included five primary ranks: species, sub-genus, genus, tribe and subfamily. The taxonomic rank of each species is cited in de Jong (2013).

Species richness was calculated as the sum of all species found in each trap.

Spearman's rank correlation was used to reveal the presence of collinearity between MIB, taxonomic diversity, taxonomic distinctness and species richness.

In order to test the effect of time since deglaciation on MIB, taxonomic distinctness and species richness, linear regression analysis was used. Before the analysis I evaluated the sensitivity of the results for the traps with just one, then at most two and finally at most three individuals. As there were no significant differences (both correlation coefficients and P-values remained unchanged) I performed the analysis using the complete dataset.

In order to evaluate whether MIB is related to the assemblages found in areas with different time since deglaciation, an Analysis of Similarities (ANOSIM), based on Jaccard's index of similarity, was performed to evaluate the similarities in the composition of assemblages recorded in the glacier forelands. Prior to performing the analyses, traps were pooled according to their time since deglaciation. A dendrogram of similarity, based on Jaccard's index, was drawn to show whether sites with the same species composition occurred in areas that had been deglaciated for same length of time. The agglomerative method used to join the clusters was the average distance between all members in the two groups (called UPGMA). The two main clusters obtained from the dendrogram were compared in terms of MIB values associated with the period of time since deglaciation, using a t-test (Gotelli \& Ellison, 2004).

All statistical analyses were performed in PAST v3.0 (Hammer et al., 2001) and SPSS v20.0 (SPSS Inc., Chicago, IL, USA).

\section{RESULTS}

The three dependent variables used in the analyses (MIB, taxonomic distinctness and species richness) were collinear. MIB was positively correlated only with taxonomic distinctness (rho $=0.20 ; \mathrm{P}=0.03$ ). On the other hand, taxonomic distinctness was positively correlated with species richness $(\mathrm{rho}=0.60 ; \mathrm{P}=0.0001)$. Linear regression revealed that MIB (ANOVA test: $\mathrm{F}_{1,114}=12.44$; $\mathrm{P}=0.001$ ), taxonomic distinctness (ANOVA test: $\mathrm{F}_{1,114}=$ 14.13; $\mathrm{P}=0.0001$ ) and species richness (ANOVA test: $\mathrm{F}_{1,114}$ $=7.46 ; \mathrm{P}=0.007)$ are all positively associated with time since deglaciation.

In particular, MIB increased gradually during succession (Fig. 1).

The ANOSIM test demonstrated that there was a significant turnover in species compositions of the assemblages, which changed with time since deglaciation (ANOSIM, R $=0.51 ; \mathrm{P}<0.007)$. The dendrogram based on Jaccard similarity values revealed two main groups of clusters of sites (group 1 and group 2, Fig. 2) with similar species composition. This analysis indicates that an important event in species turnover differed in the two groups. The clusters also differed significantly in mean MIB values ( $\mathrm{t}$-test: $\mathrm{P}=$ 


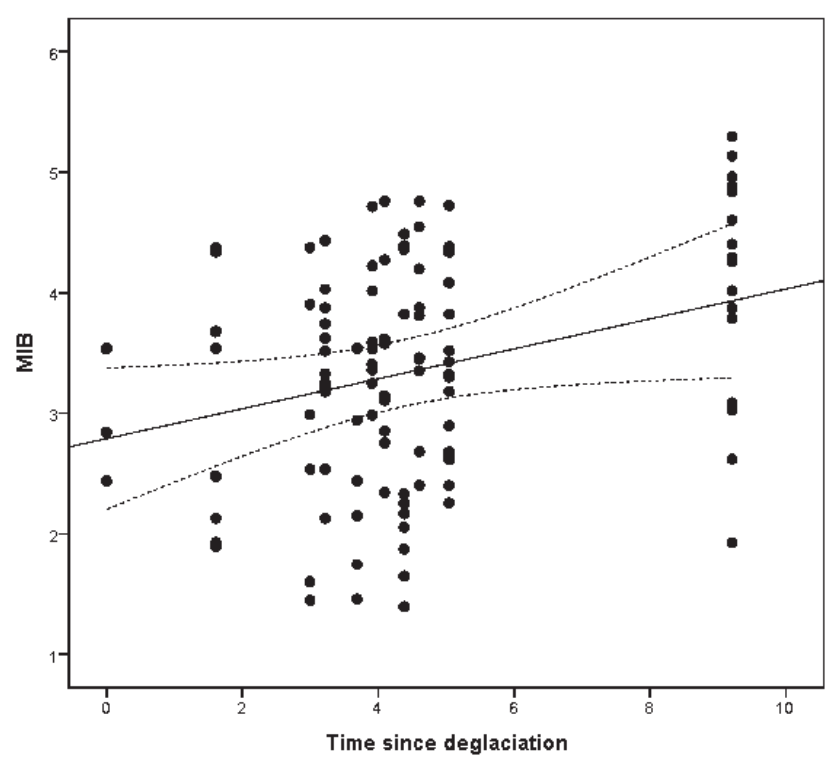

Fig. 1. The relationship between the MIB values and the time since deglaciation (both plotted on logarithmic scales) for each of the sites sampled. The bold line represents the increase in the mean MIB values of each site sampled along the temporal succession and dashed line the $95 \%$ confidence intervals.

$0.001)$ with a higher mean value for group $1(\mathrm{MIB}=53.1)$ than group $2(\mathrm{MIB}=29.3)$ (Fig. 3).

\section{DISCUSSION AND CONCLUSIONS}

The results indicate that the MIBs recorded in the glacier forelands reflect local successional stages. Therefore, the MIB index also works well for habitats different from those previously used to test it (i.e. forest sites, agroecosystems) (Schwerk et al., 2006; Schwerk \& Szyszko, 2007; Cárdenas \& Hidalgo, 2007).

There was no relationship between species richness and MIB, but MIB was positively associated with taxonomic distinctness. This means that MIB does not depend on the number of species, but on the taxonomic group (subfamily, tribe, genus or subgenus) to which each species belongs. Paschetta et al. (2013) report that taxonomic distinctness seems to be closely related to habitat diversity and func-

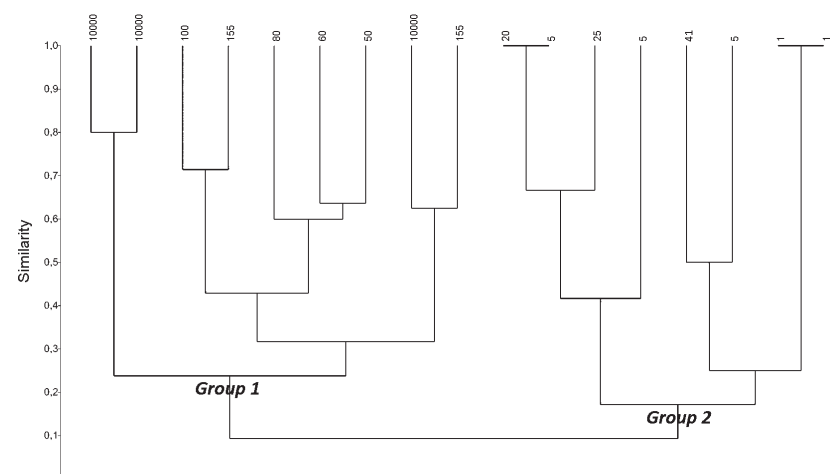

Fig. 2. Dendrogram clustering the times since deglaciation into groups based on similarity in species compositions of the assemblages. Two main groups are identified: group 1 (areas deglaciated more than 50 years ago) and group 2 (areas deglaciated less than 41 years ago).

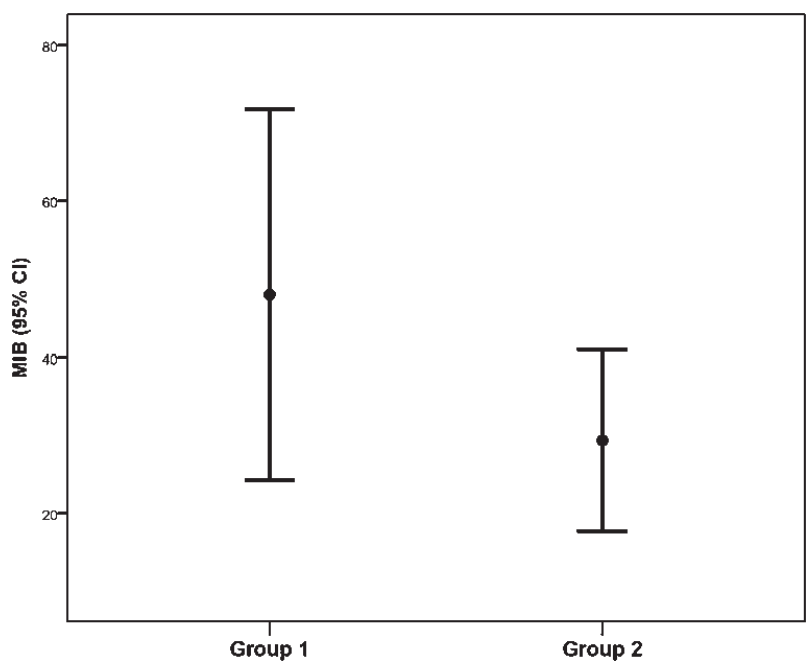

Fig. 3. Differences in the mean MIB values of the sites deglaciated more than 50 years ago (group 1) and those deglaciated less than 41 years ago (group 2).

tionality, and thus a high value of taxonomic distinctness indicates a broad taxonomic diversity. The MIB values recorded in this study are highly variable and seem to increase from just in front of the glacier to the Late Glacial substrata. This pattern can be explained in two ways. First, some traps caught very few individuals and as a consequence MIB values could be biased; Schwerk \& Szyszko (2007b) recommend that for reliable data a sample of at least 50 individuals is needed. Second, the broad taxonomic diversity recorded in the last stage of the succession underlies the observed wide range of MIB values. As the environment of the late successional stage is very heterogeneous (Gobbi et al., 2010) there are many different species there and the MIB values are very variable. Moreover, some traps located in the early and mid-successional stages yielded high MIB values, similar to those recorded for the late successional stages. These results are driven by the presence of large numbers of Carabus sylvestris and $C$. depressus, two large species that often occur abundantly on bare ground (Gobbi et al., 2007).

Furthermore, the results suggest that if taxonomic distinctness is taken into consideration the interpretation of the MIB values and evaluation of successional stages in certain ecosystems is easier. In this study, MIB and taxonomic distinctness increased from the front of the glaciers to the older sites. This means that sites closest to the glacier are characterized by low MIB values and low taxonomic distinctness, whereas those far from the glacier are characterized by high MIB values and high taxonomic diversity. Areas never reached by the glaciers during the Holocene, the Late Glacial Substrata, can be considered to represent the climax in terms of succession. These areas also had the highest MIB values and highest taxonomic distinctness. Gobbi et al. (2010) demonstrate that assemblages on Late Glacial Substrata have traits typical of stable and mature environments: are large-sized, lack functional hind wings and are autumn-breeders. Therefore, in agreement with Matthews (1992), a chronosequence of glacier retreat can 
be interpreted as a temporal sequence in the development of species assemblages, and a resource availability and disturbance/stability gradient.

Habitat age is considered to be a crucial variable in determining ecosystem functionality and processes (Bardgett et al., 2005). The results obtained using the MIB index indicate that temporal aspects may be decisive both for the composition of carabid assemblages in primary succession (Gobbi et al., 2007; Schlegel \& Riesen, 2012) and the mean individual biomass of carabid beetles.

The turnover analysis further supported the relationship between MIB and taxonomic composition of the assemblages in glacier forelands. Sites deglaciated more than 50 years ago had higher mean MIB values than those deglaciated less than 41 years ago. The latter, therefore, can be seen as an early stage of succession in the light of the results of Szyszko et al. (2000) and Jelaska et al. (2011). Their assemblages were characterized by species such as Amara quenseli and Nebria spp. These are small to medium-sized species living on wet bare ground between clumps of herbaceous vegetation (Saxifraga spp.). On the other hand, the species composition of sites deglaciated more than 50 years ago were characterized by species typical of late successional stages, for example Cymindis vaporarioum, Amara erratica, Carabus sylvestris, Leistus nitidus and Pterostichus multipunctatus (Gobbi et al., 2007; Schlegel \& Riesen, 2012), which are medium to large species and are abundant.

In summary, time since deglaciation is an important factor influencing the species composition of carabid assemblages and the MIB values recorded along chronosequence. MIB seems to be a sensitive indicator of carabid beetle successional stages in the glacier forelands, but more research is necessary before MIB can be included as an index of the stage of succession in long-term monitoring programs.

ACKNOWLEDGEMENTS. I thank Stelvio National Park for permission to carry out this research and P. Davison and T. Dixon for improving the English of this manuscript. Associate Editor (D. Boukal) and two anonymous referees, provided very helpful comments and suggestions on a first draft of this manuscript.

\section{REFERENCES}

Bardgett R.D., Bowman W.D., Kaufmann R. \& Schmidt S.K. 2005: A temporal approach to linking aboveground and belowground community ecology. - Trends Ecol. Evol. 20: 634641.

Begon M., Harper J.L. \& Townsend C.R. 1991: Ökologie. Individuen, Populationen und Lebensgemeinschaften. Birkhäuser, Basel, Boston, Berlin, 1024 pp.

Brambilla M. \& GobBi M. 2014: A century of chasing the ice: delayed colonisation of ice-free sites by ground beetles along glacier forelands in the Alps. - Ecography 37: 33-42.

Bråten A.T., Flø D., Hågvar S., Hanssen O., Mong C.E. \& AAKRA K. 2012: Primary succession of surface active beetles and spiders in an alpine glacier foreland, central south Norway. - Arct. Antarct. Alp. Res. 44: 2-15.

Cárdenas A.M. \& Hidalgo J.M. 2007: Application of the mean individual biomass (MIB) of ground beetles (Coleoptera, Carabidae) to assess the recovery process of the Guadiamar Green
Corridor (southern Iberian Peninsula). - Biodiv. Conserv. 16: 4131-4146.

Clarke K.R. \& Warwick R.M. 1998: A taxonomic distinctness index and its statistical properties. - J. Appl. Ecol. 35: 523531.

DE Jong Y.S.D.M. (ed.) 2013: Fauna Europaea. Version 2.6. Web Service available online at http://www.faunaeur.org

Gobbi M., De Bernardi F., Pelfini M., Rossaro B. \& Brandmayr P. 2006: Epigean arthropod succession along a 154-year Glacier foreland chronosequence in the Forni Valley (central Italian Alps). - Arct. Antarct. Alp. Res. 38: 357-362.

Gobbi M., Rossaro B., Vater A., De Bernardi F., Pelfini M. \& Brandmayr P. 2007: Environmental features influencing Carabid beetle (Coleoptera) assemblages along a recently deglaciated area in the Alpine region. - Ecol. Entomol. 32: 682-689.

Gobbi M., Caccianiga M., Cerabolini B., De Bernardi F., LuzZaro A. \& Pierce S. 2010: Plant adaptive responses during primary succession are associated with functional adaptations in ground beetles on deglaciated terrain. - Comm. Ecol. 11: 223-231.

Gotelli N.J. \& Ellison A.M. 2004: A Primer of Ecological Statistics. Sinauer Associates, Sunderland, MA, $492 \mathrm{pp}$.

Hammer Ø., Harper D.A.T. \& Ryan P.D. 2001: PAST: Paleontological statistics software package for education and data analysis. - Palaeontol. Electron. 4(1): 9 pp.

HODKINSON I.D. \& JACKSON J.K. 2005: Terrestrial and aquatic invertebrates as bioindicators for environmental monitoring, with particular references to mountain ecosystems. - Environ. Manag. 35: 649-666.

Hodkinson I.D., Coulson S.J. \& WebB N. 2004: Invertebrate community assembly along proglacial chronosequences in the high Arctic. - J. Anim. Ecol. 73: 556-568.

HưRKA K. 1996: Carabidae of the Czech and Slovak Republics. Kabourek, Zlín, 565 pp.

Jelaska L.S., Dumbović V. \& Kučinić M. 2011: Carabid beetle diversity and mean individual biomass in beech forests of various ages. In Kotze D.J., Assmann T., Noordijk J., Turin H., \&Vermeulen R. (eds): Carabid Beetles as Bioindicators: Biogeographical, Ecological and Environmental Studies. - ZooKeys 100: 393-405.

KAUFMANN R. 2001: Invertebrate succession on alpine glacier foreland. - Ecology 82: 2261-2278.

KAUFMANN R. 2002: Glacier foreland colonisation: distinguishing between short-term and long-term effects of climate change. Oecologia 130: 470-475.

Lövei G.L. \& SunderLAND K.D. 1996: Ecology and behaviour of ground beetles (Coleoptera, Carabidae). - Annu. Rev. Entomol. 41: 231-256.

Matthews J.A. 1992: The Ecology of Recently-deglaciated Terrain. A Geoecological Approach to Glacier Forelands and Primary Succession. Cambridge University Press, Cambridge, $386 \mathrm{pp}$.

Oerlemans J. 2005: Extracting a climate signal from 169 glacier records. - Science 308: 675-677.

Paschetta M., Giachino P. \& Isaia M. 2013: Taxonomic relatedness of spider and carabid assemblages in a wetland ecosystem. —Zool. Stud. 51: 1175-1187.

Pesarini C. \& Monzini V. 2010: Insetti della Fauna Italiana. Coleotteri Carabidi I. - Natura, Riv. Sc. Nat. 100(2): 152 pp.

Pesarini C. \& Monzini V. 2011: Insetti della Fauna Italiana. Coleotteri Carabidi II. - Natura, Riv. Sc. Nat. 101(2): 144 pp.

SCHLEGEl J. \& RieSEN M. 2012: Environmental gradients and succession patterns of carabid beetles (Coleoptera: Carabidae) in an Alpine glacier retreat zone. - J. Insect Conserv. 16: 657675. 
Schwerk A. \& Szyszko J. 2007a: Increase of Mean Individual Biomass (MIB) of Carabidae (Coleoptera) in relation to succession in forest habitats. — Wiad. Entomol. 26: 195-206.

Schwerk A. \& Szyszko J. 2007b: Mittlere Individuen Biomasse (MIB) von epigäischen Laufkäfern (Coleoptera: Carabidae) als Indikator für Sukzessionsstadien. - Angew. Carabidol. 8: 69-72.

Schwerk A., Salek P., Duszczyk M.A. \& Szyszko J. 2006: Variability of Carabidae in time and space in open areas. - Entomol. Fenn. 17: 258-268.

Serrano J. \& Gallego D. 2004. Evaluation of regeneration process and status of pine forests from Sierra Espuña (Murcia) by analysis of mean individual biomass in ground beetles. - An. Biol. (Murcia) 26: 191-211.

Szyszko J. 1983: Methods of macrofauna investigations. In Szujecki A., Szyzsko J., Mazur S. \& Perliński S. (eds): The Process of Forest Soil Macrofauna Formation after Afforestation of Farmland. Warsaw Agricultural University Press, Warsaw, pp. 10-16.
Szyszko J. 1990: Planning of Prophylaxis in Threatened Pine Forest Biocoenoses Based on an Analysis of the Fauna of Epigeic Carabidae. Warsaw Agricultural University Press, Warsaw, 96 pp.

Szyszko J., Vermeulen H.J.W. \& Den Boer P.J. 1996: Survival and reproduction in relation to habitat quality and food availability for Pterostichus oblongopunctatus F. (Carabidae, Col.). - Acta Jutl. 71: 25-40.

Szyszko J., Vermeulen H.J.W., Klimaszewski K., Abs M. \& Schwerk A. 2000: Mean individual biomass (MIB) of ground beetles (Carabidae) as an indicator of the state of the environment. In Brandmayr P., Lövei G., Zetto Brandmayr T., Casale A. \& Vigna Taglianti A. (eds): Natural History and Applied Ecology of Carabid Beetles. Pensoft, Sofia, Moscow, pp. 289294.

Received November 18, 2013; revised and accepted June 26, 2014 Prepublished online August 19, 2014

Supplementary file S1 (http://www.eje.cz/2014/071/S01.pdf). List of the carabid beetles collected at sites with different time since deglaciation. 